\title{
Teacher Professional Development, Technology, and Communities of Practice: Are We Putting the Cart before the Horse?
}

\author{
Mark S. Schlager \& Judith Fusco \\ SRI International \\ 333 Ravenswood Avenue \\ Menlo Park, CA 94025 \\ mark.schlager@sri.com judith.fusco@sri.com
}

Practice, then, both shapes and supports learning. We wouldn't need to labor this point so heavily were it not that unenlightened teaching and training often pulls in the opposite direction. Brown \& Duguid (2000, p. 129)

\begin{abstract}
Over the past decade, education reform and teacher training projects have spent a great deal of effort to create and support sustainable, scalable online communities of education professionals. For the most part, those communities have been created in isolation from the existing local professional communities within which the teachers practice. We argue that focusing on online technology solely as a mechanism to deliver training and/or create online networks places the cart before the horse by ignoring the Internet's even greater potential to help support and strengthen local communities of practice within which teachers work. In this paper, we seek guideposts to help education technologists understand the nature of local K-12 education communities of practice - specifically their reciprocal relationship with teacher professional development and instructional improvement interventions - as a prerequisite to designing online sociotechnical infrastructure that supports the professional growth of education professionals.
\end{abstract}

Keywords: Community of practice, teacher professional development, sociotechnical infrastructure, online community, activity structures

\section{Introduction}

In their book The Social Life of Information, Brown and Duguid (2000) analyze examples of learning in the context of professional practice and the ways in which information technology supports or fails to support professional learning. Failure is related to neglect of ways in which people learn, their resourcefulness in solving problems, and the communities of practice in which they participate. As the opening quotation suggests, training (and technology that supports a training model of learning) tends to pull professionals away from their practice, focusing on information about a practice rather than on how to put that knowledge into practice. Only by engaging in work and talking about it from inside the practice can one learn to be a competent practitioner. They conclude that "practice is an effective teacher and the community of practice an ideal learning environment" (p. 127). 
In S. Barab, R. Kling, and J. Gray (Eds.) Designing for Virtual Communities in the Service of Learning. Cambridge University Press. Also in The Information Society, 203-220, 2003

Over the past several years, we have been developing and refining the sociotechnical infrastructure of a virtual environment called Tapped $\operatorname{In}^{\circledR}$ (www.tappedin.org) that is intended to support the online activities of a large and diverse community of education professionals. We have described the design principles that underlie our efforts and documented how educators have used the environment for their own purposes and in the context of formal professional development (Schlager \& Schank, 1997; Schank, Fenton, Schlager, \& Fusco, 1999). We have also tracked the growth and evolution of what we have called an online education community of practice (Schlager, Fusco, \& Schank, 1998; Fusco, Gehlbach, \& Schlager, 2000; Schlager, Fusco, \& Schank, 2002).

Along the way, we have struggled with the choice of label. We have succeeded in growing and supporting a thriving community of thousands of education professionals, but the question of whether the users of the Tapped In environment collectively constitute a community of practice remains unresolved. Although we have tried ardently to cultivate a social entity that reflects all the major characteristics of communities of practice described in the literature, and in many ways have been very successful, we have struggled to define the practice. The members of Tapped In appear to participate in many, sometimes overlapping, communities of practice in and outside of the Tapped In environment (Schlager, Fusco, \& Schank, 2002; Tatar, Gray, \& Fusco, 2002; Gray \& Tatar, this volume), suggesting that Tapped In may be better described as a network of practice (Brown \& Duguid, 2000), a constellation of practices (Wenger, 1998), or a crossroads ${ }^{1}$ of multiple educator communities.

Although such distinctions may appear inconsequential on the surface, we believe that it can have important consequences for online infrastructure design (Schank et al., 1999). As an online crossroads, Tapped In has been quite successful in achieving its original goal of bringing together and forging new relationships among education practitioners, providers, and researchers from around the world on a daily basis. Thousands of different people log in each month to engage in activities that include course and workshop sessions, group meetings, and public discussions spanning a wide range of K-12 topics. Many of our members are drawn to Tapped In because they seek ideas and colleagues outside of their local practice. Others introduce their local colleagues (or, in the case of university faculty, their students) to Tapped In to demonstrate the affordances of online communities. In this way, the community grows and evolves.

\footnotetext{
${ }^{1}$ This term came from Linda Polin, Pepperdine University.
} 
In S. Barab, R. Kling, and J. Gray (Eds.) Designing for Virtual Communities in the Service of Learning. Cambridge University Press. Also in The Information Society, 203-220, 2003

In optimizing our design to cultivate and support an online community, we have almost certainly ignored or rejected design alternatives that would have supported more effectively the professional activities in which our members participate in their local context of practice (i.e., their own schools or districts). We do not regret the choices we have made, but we are concerned that, as in many professional development projects (online and face-to-face), teachers' experiences in Tapped In will remain only tangentially related to the predominant practices of professional development in their own school districts. In our eyes, that would constitute failure of our mission - helping teachers to break out of their isolation only to grow apart from their local practice professionally is not our intent.

In the conclusion to our most recent paper (Schlager et al., 2002), we began to "think aloud" about how our online community concepts and design principles might play a more integral role in local- and state-level teacher professional development. We envisioned the development of systemic (i.e., district- or statewide) online education communities of practice that serve the professional development needs of teachers and support the missions of professional development providers across a district, state, or region. We argued that, as a shared sociotechnical infrastructure, a systemic online education community of practice could not only provide more equitable access to professional development opportunities but also help build the capacity of, and provide incentives for, teachers to participate in formal and self-organized professional learning activities. Such an online infrastructure could also help build the capacity of professional development providers to offer the kinds of experiences that reflect research-derived principles and strategies.

This chapter takes up that line of thought, beginning a new stage in our research. We step back from a focus on online communities as designed and built by researchers and professional development providers to serve a particular purpose and examine communities of practice as they exist in local education systems. We seek to understand the nature of local education communities of practice, their reciprocal relationship with teacher professional development and instructional improvement interventions, and the sociotechnical infrastructure through which the community supports the professional growth of its teachers.

\section{Theoretical Underpinnings of Our Work}


In S. Barab, R. Kling, and J. Gray (Eds.) Designing for Virtual Communities in the Service of Learning. Cambridge University Press. Also in The Information Society, 203-220, 2003

TIS DRAFT 6/03

As in our prior work, we draw from the community of practice literature. The characteristics of workplace communities of practice and how members work and grow professionally within them have been documented extensively in sociological and anthropological research (Lave \& Wenger, 1991; Orr, 1996; Wenger, 1998; Cothrel \& Williams, 1999; Brown \& Duguid, 1991, 2000) outside of public education. Communities of practice are viewed as emergent, self-reproducing, and evolving entities that are distinct from, and frequently extend beyond, formal organizational structures, with their own organizing structures, norms of behavior, communication channels, and history (Brown \& Duguid, 1991; Lave \& Wenger, 1991; Barab \& Duffy, 2000; Schlager et al., 2002). Members often come from a larger professional network spanning multiple organizations, drawn to one another for both social and professional reasons. Newcomers gain access to the community's professional knowledge tools and social norms through peripheral participation in authentic activities with other members. New practices and technologies are brought into the community by leaders, newcomers, and outsiders, and are adopted by the community through the discourse of its members and the evolution of practice over time. Thus, from a community of practice perspective, one's work and one's professional development are inextricably entwined with those with whom one works.

This characterization of communities of practice has been documented in many craft and professional workplaces, but it appears to be the exception rather than the rule in workplaces that we call schools. Thus, we begin our exploration with a focused summary of research on the characteristics of effective professional development and the complex web of challenges to implementing programs that exhibit those characteristics within the traditional professional development paradigm. ${ }^{2}$ We then ask: Why do education researchers, policy-makers, district leaders, and technologists need to understand, nurture, and support communities of practice in $K$ 12 education? To understand the roles that communities of practice play in K-12 education and the relationship between education communities of practice and teacher professional development, we appeal to the richly descriptive literature on the teaching profession, teacher communities, and teacher professional development. Finally, we ask: What can education technologists do to help nurture and support communities of practice in K-12 education? By understanding the characteristics of communities of practice and the forms they take in the education profession, we hope to find more effective ways to apply what we have learned about online community 
In S. Barab, R. Kling, and J. Gray (Eds.) Designing for Virtual Communities in the Service of Learning. Cambridge University Press. Also in The Information Society, 203-220, 2003

TIS DRAFT 6/03

processes and structures to foster more effective, scalable, and sustainable professional development in local education systems. We enumerate eight characteristics of education communities of practice and their implications for the design of online capabilities to support the roles that such communities can play in the professional development of K-12 education professionals.

\section{Teacher Professional Development: The Vision and the Reality}

To design online technology and services that support effective professional development, education technologists must understand the participants, processes, and structures that comprise effective professional development, the extent to which existing professional development projects reflect those components, and the local professional norms and practices that support or inhibit effective professional development. Researchers (Putnam \& Borko, 2000; Smylie, Allensworth, Greenberg, Harris, \& Luppescu, 2001; Darling-Hammond \& Ball, 1997; Loucks-Horsley et al., 1998; Little, 1993), practitioners (Wilson \& Berne, 1999; AACTE, 2000), and policy-makers (Rényi, 1996; PCAST, 1997; National Commission on Mathematics and Science Teaching for the $21^{\text {st }}$ Century, 2000) are converging on a shared vision of the characteristics of effective teacher professional development. Professional development is viewed as a career-long, context-specific, continuous endeavor that is guided by standards, grounded in the teacher's own work, focused on student learning, and tailored to the teacher's stage of career development. Its objective is to develop, implement, and share practices, knowledge, and values that address the needs of all students. It is a collaborative effort, in which teachers receive support from peer networks, local administration, teacher educators, and outside experts. Formal school-based and outside professional development programs are aligned with one another and balanced with informal professional development activities.

We recognize that this brief description does not capture the complexities and nuances inherent in the vision, but we hope it conveys that teacher professional development is more than a series of training workshops, institutes, meetings, and inservice days. It is a process of learning how to put knowledge into practice through engagement in practice within a community of practitioners. The description also suggests that professional development can be treated as a socioorganizational system that requires communication and close cooperation among several

\footnotetext{
${ }^{2}$ For a more in-depth overview, we encourage the reader to refer to Loucks-Horsley, Hewson, Love, and Stiles (1998)
} 
In S. Barab, R. Kling, and J. Gray (Eds.) Designing for Virtual Communities in the Service of Learning. Cambridge University Press. Also in The Information Society, 203-220, 2003

TIS DRAFT 6/03

stakeholder groups to assure access to professional development opportunities for all teachers, continuity and cohesion of professional development pedagogy across providers, capacity to support sustained adoption and practice, sharing of knowledge and professional norms of practice, and formation of coherent policies. We conjecture that fulfilling these requirements is where a local community of practice, and the sociotechnical infrastructure that supports it, can play a crucial role in achieving effective professional development district-wide.

This vision, and the system it implies, have been difficult to put into practice. Studies of school-based professional development, programs developed and implemented by outside providers, and informal teacher networks at both the local (McLaughlin \& Mitra, 2001; Smylie et al, 2001) and national levels (Corcoran, Shields, \& Zucker, 1998; Garet, Porter, Desimone, Birman, \& Yoon, 2001) have consistently found that professional development programs are disconnected from practice, fragmented, and misaligned. Many programs lack key pedagogical, content, and structural characteristics of effective professional development that are needed by the teachers they serve. Few professional development providers have the resources to address all stages of career development or the capacity to provide support on an ongoing basis. There is little coordination among providers or continuity across stages of the career development ladder, creating gaps and redundancies that hamper teachers' ability to assess and satisfy their ongoing professional development needs.

Obstacles to professional development have also been documented within schools themselves. Local values and norms of practice have proved formidable barriers to effective professional development. For example, a common challenge is the reluctance of teachers to engage in inquiry or dialogue that critiques the practice of their peers (Grossman, Wineburg, \& Woolworth, 2000; Barab, MaKinster, \& Scheckler, this volume). Research has cited the importance and difficulty of building trusting and respectful relationships across school departments (Grossman et al., 2000) and career development levels (Hartcollis, 2000). Teachers also find it difficult to reflect on their own practice, perhaps because teachers' classroom practice is closely tied to their identity as a person, because teachers lack certain professional dispositions (Ball \& Cohen, 1999), or because teaching has largely developed a culture of privacy (Little, 1990).

Clearly, the challenges to achieving the kinds of work-embedded professional development processes envisioned here are formidable and multifaceted. Because the problems extend beyond

and to Darling-Hammond and Sykes (1999). 
In S. Barab, R. Kling, and J. Gray (Eds.) Designing for Virtual Communities in the Service of Learning. Cambridge University Press. Also in The Information Society, 203-220, 2003

the traditional foci of professional development research (e.g., content, pedagogy, and assessment) into the realm of social and organizational issues, they have been extremely resistant to efforts by professional development programs and systemic reform projects to address them (Stein, Silver, \& Smith, 1998; Corcoran et al., 1998; Smylie et al., 2001; Gallego, Hollingsworth, \& Whitenack, 2001; Blumenfeld, Fishman, Krajcik, \& Marx, 2000). The state of research in this area is aptly summarized by Wilson and Berne (1999): "across this incoherent and cobbled-together nonsystem, structured and unstructured, formal and informal, we have little sense ... of what exactly it is that teachers learn and by what mechanisms that learning takes place" (p. 174).

This chapter is not intended to offer a conceptual or technological silver-bullet solution to those challenges, but we do describe a conceptual thread weaving through recent teacher research, policy studies, and evaluations of systemic reform programs - reference to the characteristics and benefits of communities of practice. We take up that thread in an attempt to derive lessons that will guide research into the development of sociotechnical infrastructures that can help practitioners and policy-makers overcome some of the challenges to achieving the vision above.

\section{Teacher Professional Development and Communities of Practice}

Researchers and reform advocates consistently cite participation in communities of practice as an integral factor in achieving effective, sustainable professional development systems. For example, a recent study of professional development in Chicago (Smylie et al., 2001) indicates that a teacher's community of practice can play both catalytic and direct roles in the teacher's professional development.

A professional community characterized by a focus on student learning, peer collaboration, and reflective dialog provides social and normative support for teacher participation in professional development.... (pp. 57-58)

In schools with strong norms for innovation and strong professional communities, teachers find motivation, direction, and accountability for continuous learning and development. They find among their colleagues sources of new ideas, intellectual stimulation, and feedback essential to deepen learning and promote instructional 
In S. Barab, R. Kling, and J. Gray (Eds.) Designing for Virtual Communities in the Service of Learning. Cambridge University Press. Also in The Information Society, 203-220, 2003

change. They also find encouragement and safety in challenging taken-forgranted assumptions, risk-taking, and experimenting with new ideas. (p. 50)

The first quote suggests that a teaching professional's community of practice is a preexisting social entity (in relation to a particular professional development intervention) that can (at least under some circumstances) serve an enabling or catalytic function, establishing and spreading professional norms of practice, encouraging collaboration among community members, and instilling dispositions (Ball \& Cohen, 1999) needed for effective professional development. The second quote also suggests that a teacher's community can have a direct impact on development through various forms of informal collegial interaction. In a national survey of teachers, Riel and Becker (2000) found significant differences in the classroom practices of professionally engaged teachers and those who engaged in "private" practice, isolated in their classrooms. Teachers who played important roles in a larger educational community were more likely to use constructivist and collaborative instructional strategies in their classrooms, while private-practice teachers were more likely to use direct instruction and individualized learning tasks.

The recognition that communities of practice can play important direct and catalytic roles in teacher learning has spurred great interest in how to harness the power of communities of practice in the context of systemic school reform and professional development projects. For example, Blumenfeld and her colleagues (2000) argue that "instructional reform requires a school culture that supports professionalism and provides opportunities for sharing, risk taking, and reflection among teachers about pedagogy and student learning. It is also more likely to take root when there are norms of open communication and cooperation among administrators and teachers...." (p. 151). McLaughlin and Mitra (2001) argue that sustaining large-scale theory-based reform efforts "requires a community of practice to provide support, deflect challenges from the broader environment, and furnish the feedback and encouragement essential to going deeper" (p. 10). In their study of one such effort, they found that a local community of practice was the primary vehicle for learning, for sustaining project norms and values, and for inducting new teachers into the reform-based culture.

But the questions of what assemblage of people constitute a community of practice in education and how, and under what conditions, a community of practice catalyzes positive learning outcomes remain largely unresolved (for more discussion, see Riel \& Polin, this volume). If 
In S. Barab, R. Kling, and J. Gray (Eds.) Designing for Virtual Communities in the Service of Learning. Cambridge University Press. Also in The Information Society, 203-220, 2003

TIS DRAFT 6/03

communities of practice can be so powerful and useful to professional development, why don't more school districts reflect the conditions described in the Smylie et al. passages just cited or exhibit the characteristics of effective professional development described in the vision above? What is it about communities of practice that supports the effective professional development of their members? Is there a relationship between a community of practice and each individual professional development intervention, such that if we can find ways to enhance the functioning of the former, the latter will also improve?

Although on the surface the questions we raise appear to have more to do with policy and professional development strategy than technology, we argue that the answers to these questions are also central to the design of technical infrastructure that supports the professional development of our nation's teachers. The large scale and distributed nature of many reform projects, along with an imperative to sustain and scale up change, have led many research and development projects to explore the role of the Internet in delivering teacher training and creating online communities that can help sustain the learning after formal professional development (Ruopp, Gal, Drayton, \& Pfister, 1993; Schlager \& Schank, 1997; Palloff \& Pratt, 1999; Marx, Blumenfeld, Krajcik, \& Soloway, 1998; Barab et al., this volume).

Today, it would be rare to find a professional development project of any magnitude and duration that does not use at least some generic Internet technologies to foster dialogue and/or information sharing. Yet, simply having the ability to interact more frequently and for longer durations online than face-to-face does not translate directly into high-quality learning experiences or sustainable communities (Hawkins, 1996; Feldman, Konold, \& Coulter, 2000). Few professional development projects have resulted in online communities that are sustainable enough to support teachers as they engage in the extended process of classroom reform (Donnelly, Dove, Tiffany, Adelman, \& Zucker, 2000) or scalable enough to support all teachers as they enter the profession and grow professionally toward mastery (Corcoran et al., 1998).

Perhaps in applying Internet technology to deliver teacher training and create online teacher networks, we have placed the cart before the horse by ignoring the Internet's even greater potential to help support the local communities of practice within which teacher training and networking take place. We are convinced that more traction might be gained by understanding and, as appropriate, using Internet technology to help strengthen, grow, sustain, and/or change an extant education community's membership, culture, structures, and processes. We next explore this 
In S. Barab, R. Kling, and J. Gray (Eds.) Designing for Virtual Communities in the Service of Learning. Cambridge University Press. Also in The Information Society, 203-220, 2003

TIS DRAFT 6/03

supposition and its implications for the role and design of online technology in support of local education communities of practice.

\section{Education Communities of Practice in the Wild}

The nature of education communities of practice and the ways they come to play a supportive role in teacher professional development are not well understood. In education research, the term community has been invoked as a classroom strategy (Bransford, Brown, \& Cocking, 1999), a professional development strategy (Ruopp et al., 1993; Wilson \& Berne, 1999), an alternative to formal professional development (Schlager \& Schank, 1997), a small group of educators engaged in some activity (Scribner, Cockrell, Cockrell, \& Valentine, 1999; Grossman et al., 2000), and a label to instill a sense of trust and interdependence among the members of a group (Palloff \& Pratt, 1999; Loucks-Horsley et al., 1998). ${ }^{3}$ A first step in understanding the leverage that technologists can bring to supporting communities of practice and their role in promoting effective professional development is to detect them (Brown \& Duguid, 1991). In our effort to understand the scope, boundaries, and characteristics of education communities of practice, we turned to a rich body of literature on teacher learning and professional practice. ${ }^{4}$

Breaking down artificial walls. Professional development research and implementation projects often treat community of practice as an artifact to be built in the context of some form of intervention, suggesting that infrastructure for supporting interventions and communities of practice are synonymous and that both are divorced from practices and practitioners that are not part of the intervention. We conjecture that this artificial distinction between community inside and outside the intervention may be one reason why many professional development and reform projects remain islands of exemplary practice in a sea of systemwide dysfunctional practice. Studies describing professional development interventions that have been sustainable and scalable over time have found a quite different relationship, in which an extant education community of practice coalesces around, interacts with, and influences formal teacher professional development and reform programs (Elmore, 1996).

\footnotetext{
${ }^{3}$ In their chapter in this volume, Riel and Polin provide an excellent analysis of the distinctions among different types of education communities.

${ }^{4}$ Wilson and Berne (1999) and Cochran-Smith and Lytle (1999) provide illuminating overviews of the field. Lortie (1975) and, more recently, McLaughlin and Talbert (2001) provide excellent overviews of the characteristics of teaching practitioner communities, particularly in relation to school and district administration.
} 
In S. Barab, R. Kling, and J. Gray (Eds.) Designing for Virtual Communities in the Service of Learning. Cambridge University Press. Also in The Information Society, 203-220, 2003

TIS DRAFT 6/03

Much of what a teacher needs to know (and know how to do) is learned in the context of practice. Little (2001) suggests that resources for the improvement of teaching are created through interaction among teachers and others in what she calls traditional communities (as opposed to those that are organized specifically around a particular intervention) as they work with teaching and learning artifacts in the context of daily practice. She suggests that "it is in the ordinary, mundane exchanges among teachers...that professional community is forged and opportunities to learn are created or foreclosed” (p. 8). To help nurture, sustain, and spread instructional improvement throughout an entire education system and reverse the decontextualization, misalignment, and fragmentation of professional development, we must understand communities of practice as integral components of education systems apart from professional development interventions. We must recognize the reciprocal and sometimes dialectical relationship between the norms and practices of the extant community and those of a particular intervention. Only then can we design infrastructure to support the processes of systemwide improvement.

Extending the boundaries. Most studies of education communities of practice focus on the activities of small groups of educators in individual schools, suggesting that our analytical lens, and thus our infrastructure designs, should focus on small, relatively homogeneous groups (Grossman et al., 2000). Recently, however, reports have begun to suggest that teachers need to form communities with colleagues and experts outside their own schools or districts (Hawkins, 1996; Darling-Hammond \& Ball, 1997; PCAST, 1997; Web-based Education Commission, 2000; National Commission on Mathematics and Science Teaching for the $21^{\text {st }}$ Century, 2000). This research raises the question of what the boundaries of education communities of practice should be. Do small-scale studies capture the structures and processes of communities of practice or only the characteristics of particular factions within them?

McLaughlin and Talbert (2001) point to the importance of the relationship between district and school staff in supporting teacher communities. They describe both the negative effects on professional development of an antagonistic relationship and the positive effects where the district office and the local teacher community work together. In one exemplary district, they describe how professional development is "planned by teachers and implemented by the district" (p. 111). District staff also serve communication and brokering roles on behalf of teachers. McLaughlin and Talbert conclude that in strong district communities, "shared norms, values, and expectations that support teacher innovation are communicated throughout the district." In contrast, weak 
In S. Barab, R. Kling, and J. Gray (Eds.) Designing for Virtual Communities in the Service of Learning. Cambridge University Press. Also in The Information Society, 203-220, 2003

TIS DRAFT 6/03

district communities are "fractured by disputes, disrespect, and inconsistent leadership" (p. 114). Similarly, Elmore (1996) describes how in New York City's District 2 "professional development activities are specifically designed to connect teachers, principals, professional developers, and district administrators with each other and with outside experts around specific problems of practice" (p. 28).

These studies suggest to us that all education professionals - those who work in the schools, district leadership, and outside professional development partners - play a part in establishing values and perpetuating norms of instructional improvement; fostering communication and cooperation; building human capacity for coaching, mentoring, and peer support; sharing tools and artifacts; and building the social networks and infrastructure needed to generate and diffuse new knowledge. When these stakeholder groups work together as a community-communicating, cooperating, building trusting reciprocal relationships, and sharing norms, values, tools, and accountability for instructional improvement_-improvement can occur (Elmore, 2000). How these sociocultural preconditions for improvement come into being districtwide and what sociotechnical structures enable them to work are questions that require empirical research aimed at understanding the sociocultural processes of district communities of practice.

\section{Aligning Community Structures with Professional Development Activity Structures}

To help us understand the sociotechnical structures needed to support, nurture, and harness the power of education communities of practice, we need a framework for representing the structural relationships among a community of practice, individual practices, and professional development projects. The Activity Theory framework (Engeström, 1987, 1999; Mwanza, 2001; Cole \& Engeström, 1993; Blanton, Mooremn, \& Trathen, 1998) provides a good first step, enabling us to zoom in on individual groups and their activities and then dolly back to view those activities in the context of the larger community of practice.

Briefly, the core of the Activity Theory framework focuses on the activities in which individuals and groups (called subjects) engage. As depicted in Figure 1, subjects engage in actions (e.g., dialogue, construction, search) to accomplish the object (also called objective) of the activity, which leads to some outcome(s). Activities are mediated by the tools (technical and conceptual) and other artifacts that are available to the subjects. Activities take place in the context of, and are influenced by, a surrounding community. The community exerts influence on 
In S. Barab, R. Kling, and J. Gray (Eds.) Designing for Virtual Communities in the Service of Learning. Cambridge University Press. Also in The Information Society, 203-220, 2003

TIS DRAFT 6/03

the activity through the mediation of established rules (i.e., values, norms of behavior, dispositions toward inquiry, trust, and commitment), tools that have been institutionalized in the community, and division of labor (the allocation of roles and responsibilities).

Insert Figure 1 here

We find the framework useful in understanding the relationship between the community engaged in a professional development project and the community (or communities) of practice from which the teachers involved in the project have come. Both can be represented by similar activity system diagrams. The key to understanding the relationship between the two, and thus the roles that a community of practice can play in professional development activities, is the degree of alignment in tools, rules, and division of labor.

Professional development programs typically involve a selected group of teachers engaged in a prescribed, highly structured set of interventions to accomplish specific learning objectives. We have found it useful to describe this type of assemblage as a community of purpose. ${ }^{5}$ From the professional development provider's perspective, the social context is the program and the participants and staff are the community. The norms of engagement and tools to be employed are designed to support a particular pedagogy for a specified duration. Barab et al. (this volume) and Grossman et al. (2000) offer descriptive accounts of how professional development activities of teachers are influenced by the tools, rules, and division of labor established by leaders of a professional development project and the tensions created when forging a new community of purpose.

The framework highlights the fundamental relationship between the activity structures of professional development projects (and other professional activities, such as examining student work, lesson study, etc.) and the existing structures at each teacher's place of practice - the school. Imagine, for example, that 50 teachers are invited by a university to participate in a professional development project. The project (the activity) is designed to train the teachers (the subjects) to use a particular set of inquiry methods and technologies (tools) that have not been part of the teachers' prior repertoire or their schools' infrastructure (the object). The teachers are asked to take on new collaborative roles (division of labor) based on values and social norms that are

\footnotetext{
${ }^{5}$ We first heard this term from Vicki Suter. Riel and Polin (this volume) use the term task-based learning community.
} 
In S. Barab, R. Kling, and J. Gray (Eds.) Designing for Virtual Communities in the Service of Learning. Cambridge University Press. Also in The Information Society, 203-220, 2003

TIS DRAFT 6/03

internal to the project. The participants are also encouraged to develop trust in and form a lasting community with one another in the hope that they will support one another (outcome 1) in applying what they have learned (outcome 2) and disseminate the knowledge they gained to other teachers in their schools (outcome 3).

Misalignment. The professional development project may overlap to a greater or lesser extent with the universe of prior activities, tools, values, and norms of practice that the 50 teachers bring to the activity from their practice. It would not be difficult to imagine that at least some of the teachers come from schools where outdated conceptual tools, inadequate technological tools, an entrenched culture of privacy, and top-down allocation of roles and responsibilities are the norm. The activity diagram also brings into focus some of the challenges faced by staff and teachers in many professional development projects. For example, the participants (and, in many cases, the staff) have no prior history with one another or the tools they are expected to use to achieve the object. They must learn to use new tools and negotiate new roles and rules of engagement, resulting in a great deal of "overhead" activity before they can focus on the object of the activity (Schlager et al., 2002).

The diagram also encourages us to ask what happens to the knowledge and skills developed in the professional development project and whether the intended outcomes are realized in practice (e.g., sustained improvements in teaching and learning outcomes; dissemination of new knowledge, tools, and practices). We might imagine problems arising when the teachers return to their classes with their new palette of activities, rules, tools, and roles and must concurrently apply them in their own practice and introduce them to their colleagues. Many find that the sense of community that they established with one another takes a back seat to the demands of their daily responsibilities. They are too busy to support one another as they try to apply their new knowledge and skills in their own teaching and try to "disseminate" their new knowledge and skills. Nor can the returning teachers count on support from their local communities of practice. Other local professional development providers and accomplished teachers within the local communities of practice (neither of whom were part of the summer institute) can offer little support because the tools and strategies employed by the "outsiders" are unfamiliar to them. In some cases, the returning teachers find that they are no longer in tune with, and therefore are marginalized by, their colleagues. 
In S. Barab, R. Kling, and J. Gray (Eds.) Designing for Virtual Communities in the Service of Learning. Cambridge University Press. Also in The Information Society, 203-220, 2003

TIS DRAFT 6/03

Alignment. In contrast to the scenario just described, imagine that the same professional development project taking place within the kinds of community of practice on which Smylie et al. (2001), Stein et al. (1998), McLaughlin and Talbert (2001), and others base their descriptions of the catalytic properties of a community of practice. When professional development is embedded in a strong community of practice focused on instructional improvement, the community of practice owns a stake in the outcome of the activity. As a result, the success of the activity (object) and the outcomes of the activity become a community-wide responsibility (division of labor). For example, Stein et al. (1998) describe how a mathematics professional development project was implemented in the context of ongoing reform in a middle school. They describe an array of activities that they viewed as different from the support that teachers attempting innovation typically receive. "Although some of the assistance activities can be seen as pedagogically structured, event-specific occasions for teacher assistance (e.g., MME workshops, elective coursework, monthly staff development meetings, retreats), others were more informal and ongoing (e.g., teachers mentoring teachers, ongoing classroom visits by consulting teachers, tagging up). Still others represented opportunities to actually do the work of the project" (pp. 26-27).

The extant community forms a social support structure that can help a new professional development project introduce its teachers to new knowledge and skills in the context of conceptual tools, rules, and allocation of roles that are already well established in the community and therefore familiar to the participants. After a professional development project ends, the community reabsorbs the participating teachers into its ranks, providing support structures that can help sustain the teachers' nascent collaborative efforts and collegial relationships. At the same time, the community benefits from the infusion and spread of knowledge gained by the teachers in the project, thus helping teachers who have not participated in formal projects take charge of their own professional development (Koppich, Asher, \& Kerchner, 2002; Rényi, 1996). Individual professional development projects also become a source of new community members with new skills, which enables the community of practice to grow, spread innovation, and reproduce itself (Barab \& Duffy, 2000).

Community as catalyst. The activity framework suggests that the catalytic effects of an education community of practice on professional development stem from the alignment of the community's existing rules and tools, as well as a division of labor that draws members of the 
In S. Barab, R. Kling, and J. Gray (Eds.) Designing for Virtual Communities in the Service of Learning. Cambridge University Press. Also in The Information Society, 203-220, 2003

TIS DRAFT 6/03

community of practice into a particular activity for ongoing support and expertise. When the tools, rules, and division of labor experienced in a particular professional development activity are aligned with those of the established culture at the teacher's school (as well as with other professional development activities), the community itself also benefits. Figure 2 illustrates the community processes that can support capacity building, knowledge building, and the spread of innovative ideas. The arrows in the diagram illustrate how the community serves as a memory and diffusion mechanism for new ideas, tools, and outcomes of the project. The curved arrow indicates that knowledge and capacity generated in individual activities make their way back into the community in three forms: (1) the new values, skills, and expertise of the members of the group return to the community as those members participate in new activities with other members of the community; (2) the group may create new artifacts (e.g., rubrics, lessons) that become part of the community's knowledge base; (3) the tools used by the group (e.g., video cases, eportfolios, modeling and simulation tools) and knowledge of how to use them make their way into community discourse and other activities (Hoadley \& Pea, 2002). The vertical double-headed arrow indicates that the project both uses tools that exist within the community and introduces new tools to the community.

\section{Insert Figure 2 here}

Research describing successful districtwide professional development systems that are integrated with the district's community of practice in this way (i.e., most or all teachers in the district are involved) to achieve collective improvement is rare, but exemplary instances do exist (e.g., Koppich, Asher, \& Kerchner, 2002; Honey, Carrigg, \& Hawkins, 1998; Elmore \& Burney, 1999). One such effort is the 8-year-old Union City Online project in Union City, New Jersey, a district of 11 schools serving 10,000 inner-city students in grades K-12. All professional development programs in Union City are designed to respond to the evolving needs of the educator community. Each follows a five-stage process that involves formal and informal, largeand small-group activities (Honey et al., 1998): Awareness, Practice, Sharing, Peer Coaching, and Mentoring. District leaders and researchers cite reforms in cultural norms as key preconditions for establishing curricular reforms, helping "to establish both a climate and an infrastructure that support and embrace innovation" (p. 136). These changes in norms include collaborative 
In S. Barab, R. Kling, and J. Gray (Eds.) Designing for Virtual Communities in the Service of Learning. Cambridge University Press. Also in The Information Society, 203-220, 2003

TIS DRAFT 6/03

decision-making among school staff, district administrators, researchers, and unions and ownership of curricular changes by the teaching community.

Another example of effective integration of practice and professional development in a districtwide system is New York City's District 2, a district of 48 schools serving 22,000 students in grades K-8. Elmore and Burney (1999) describe how over more than ten years the district has evolved a strategy for the use of professional development to improve teaching and learning that "consists of a set of organizing principles about the process of systemic change and the role of professional development in that process," along with specific models of staff development that focus on "systemwide improvement of instruction" (p. 266). These models include a Professional Development Laboratory staffed by an expert "teacher in residence," peer visitation, an advising network, and outside consultants who work directly with teachers at their schools to solve concrete problems or develop new instructional interventions.

To be clear, we are not claiming that a strong community of practice was the root or primary cause of successful reform in these two districts. The two districts' policies, leadership, and reform strategies (along with an acute sense of urgency) were the primary drivers of improvement. Those drivers sparked cultural changes within the community of practice that enabled the community to enact, sustain, and spread new norms and activities. In both these cases, the local education community of practice now helps build the capacity of, and provides social incentives for, teachers to participate in formal and self-organized activities for professional growth. In both cases, the community helps build the capacity of professional development providers to offer high-quality activities that are aligned with the needs and professional norms of the community members. In both, we see communication channels, shared norms of practice and cooperation among stakeholder groups, continuity and cohesion across providers, and the capacity to support sustained adoption within the community of practice.

Community infrastructure as accelerant. Whether and how these catalytic functions can be improved and accelerated by improving the community's sociotechnical infrastructure remains a question. Research is needed to understand where weaknesses, gaps, and lack of capacity persist and to develop ways in which the appropriate use of online technology might overcome them. The Activity Theory framework focuses our investigation on the intersection of tools, rules, and division of labor between the professional development activities and the community. One example coming out of research on theory-based reform is the need to more effectively convey to 
In S. Barab, R. Kling, and J. Gray (Eds.) Designing for Virtual Communities in the Service of Learning. Cambridge University Press. Also in The Information Society, 203-220, 2003

TIS DRAFT 6/03

teachers the "first principles" on which the reform practices are based (McLaughlin \& Mitra, 2001). If we think of these first principles as conceptual tools, without which the community cannot build sustainable reform, we begin to see that teachers must become facile with those tools before they can learn to construct new practices that are robust (the object). Using traditional professional development approaches, such a process can take several years per cadre of teachers. Perhaps a different division of labor, supported by a more effective communication infrastructure, could help new conceptual tools become part of the community culture more quickly and sustainably.

Another issue that has been a growing concern of many districts is their capacity for mentoring, coaching, and peer support. Many states are enacting policies that mandate those forms of informal professional development for teachers at all stages of the career development continuum (National Commission on Teaching and America's Future, 1996). However, few local networks or programs have the expert capacity to provide the frequency and duration of contact with mentors and coaches needed to address the challenges of teacher retention and renewal. Accomplished practitioners who would serve as coaches and mentors are in shortest supply where they are needed most, in schools with high rates of underqualified teachers (Shields, Esch, Young, $\&$ Humphrey, 2000) and underperforming students. This capacity issue suggests that we look closely at the models for allocating expertise (division of labor) in the programs (typically, a huband-spoke model) and the opportunities for developing new models that make better use of the expertise that resides in the larger community of practice (a network or matrix model). Online environments could help enact and support those new organizational models, thereby increasing access to the right expertise at the right time.

\section{Correcting Dysfunctional Communities of Practice}

The literature clearly suggests that a strong community of practice can play an integral role in the professional development of a district's teaching workforce, and the Activity Theory framework points to social structures through which a community of practice comes to be a positive force. However, the mere existence of a community of practice does not imply that the community is a well-functioning social entity or a positive catalyst for effective professional development; it can also be dysfunctional in a number of ways that (along with other factors) can militate against improvement (McLaughlin \& Talbert, 2001; Wenger, 1998; Schwen, this volume). 
In S. Barab, R. Kling, and J. Gray (Eds.) Designing for Virtual Communities in the Service of Learning. Cambridge University Press. Also in The Information Society, 203-220, 2003

TIS DRAFT 6/03

We need to detect when, how, and why a community is exhibiting dysfunctional symptoms in order to understand how to correct them.

Like other large social entities, an education community of practice is a complex beast. A strong community can wield the power to enact policies or subvert them, foster change or resist it, spread innovation or impede it. A community of practice is also subject to influence from formal policies and hierarchies. It can be subordinated, undermined, or disrupted, either deliberately or inadvertently, through acts (reorganization, changes in leadership, or new policies) and omissions (e.g., not providing opportunities, tools, and support for communication and collaboration) of the formal organizational leadership (department chairs, principals, superintendents, school boards, and unions) (Scribner et al., 1999). The community itself can exhibit strong or weak leadership, foster or inhibit member diversity, and support dense webs of social relationships or sparse, disconnected threads of communication. Nor is a community of practice inherently a unifying, cooperative entity. Members can form competing factions or simply not interact with one another. A community can be so weak and fractious as to appear to be multiple communities.

Incompatibilities in culture, leadership, tools, and cooperation both within and between stakeholder groups in a local education community of practice can hinder development of an effective system of professional development. Many schools have a history of separation among teachers across disciplinary lines and career stages, of communication channels that inhibit rather than support professional networking, of discouraging informal leadership, and of erecting barriers between inside and outside expertise (Loucks-Horsley et al., 1998). All of these factors can promote a culture of privacy and autonomy that can reinforce ineffective professional development strategies and discourage collaboration and sharing of expertise and resources (Little, 1990; Elmore, 2000).

We also know that, under some circumstances, dysfunctional district communities of practice can change for the better. The Union City and District 2 examples demonstrate that dysfunctional communities of practice can, over several years, grow a strong, cohesive culture that supports fundamental systemwide improvement. Elmore (2000) gives an eloquent account of how policies and leadership focused on instructional improvement can foster such change. What remains unclear is the role that community of practice infrastructure can play in supporting, and perhaps accelerating, the evolution from dysfunctional to strong, well-functioning community of practice. Can the efforts of education technologists help promote changes in sociotechnical infrastructure 
In S. Barab, R. Kling, and J. Gray (Eds.) Designing for Virtual Communities in the Service of Learning. Cambridge University Press. Also in The Information Society, 203-220, 2003

that can improve the health of the community? Can they help a strong but entrenched educator community embrace change? Can they help unify a fractious community?

There is evidence that online sociotechnical support structures and pedagogically sound online professional development activities can foster "healthy" cultural norms, membership diversity and growth, distributed leadership, public and private dialogue, and professional networking on a large scale (Constant, Sproull, \& Kiesler, 1996; Derry, Gance, Gance, \& Schlager, 2000; Dunlap, Neale, \& Carroll, 2000; Evertson, Smithey, \& Hough, 2000; Fusco et al., 2000; Ruopp et al., 1993; PCAST, 1997; Schlager et al., 1998, 2002; Web-based Education Commission, 2000; National Commission on Mathematics and Science Teaching for the $21^{\text {st }}$ Century, 2000). To our knowledge, however, such strategies have not been applied systematically to the challenge of diagnosing and helping to correct dysfunctional aspects of education communities of practice. If we can bring online community strategies to bear on the ills of education communities of practice, we may be able to shorten the time it takes to establish the norms, values, and relationships needed to support systemwide improvement, increase the likelihood that healthy norms and practices will take root, and thereby decrease the risk that instructional reform efforts will falter or fail.

\section{Guideposts for Technology Design That Supports System-Wide Improvement}

Throughout this chapter, we have discussed several highly interwoven characteristics of communities of practice that we believe are particularly salient to understanding how communities of practice differ from other groupings of education professionals, how they exhibit symptoms of dysfunction, and how to harness their power in support of teacher professional development and instructional improvement. In this section, we attempt to untangle the characteristics we have discussed and suggest ways in which online sociotechnical infrastructure might be used to nurture and support local education communities of practice. We do not intend the following descriptions below to be complete definitions but rather a set of guideposts that together form a conceptual framework for research. Nor do we claim that the design implications we draw are the only implications that can be drawn; they are intended as examples that we hope will spur the reader to think of and research new designs for online infrastructure to support education communities of practice.

Guidepost 1. Learning Processes. The growing interest in community of practice concepts in teacher professional development stems largely from the rich and compelling descriptions of how 
In S. Barab, R. Kling, and J. Gray (Eds.) Designing for Virtual Communities in the Service of Learning. Cambridge University Press. Also in The Information Society, 203-220, 2003

TIS DRAFT 6/03

newcomers enter and learn the ropes of workplace communities. Learning is viewed as a social activity that occurs primarily in the context of work (as opposed to training) as new and lessskilled members participate peripherally in activities with more-experienced colleagues and as journeymen take on new roles on a path toward expertise. Informal learning opportunities occur regularly in the context of daily practice, typically in the form of focused episodes dealing with real problems. Support from peers and more-accomplished colleagues is common; access to and interaction with the master practitioner is relatively infrequent. New ideas are often learned through peer networks that transcend organizational boundaries. Formal training supplements informal learning to build competencies that contribute to the collective enterprise.

Countless online learning initiatives and many e-learning systems justify their designs and approaches on the basis of this characterization of learning relationships and processes.

Unfortunately, in most cases, the designs of online tools and pedagogies do not support the social structures that promote community learning processes. For example, course management technologies used in most e-learning applications (e.g., WebCT and Blackboard) are designed to support highly structured, university-style learning situations and therefore may not be the most appropriate for informal, highly contextualized learning in an education community of practice. Only people who are officially part of the course are part of the "community"; when the course is over, so is the community. Such technologies may actually hinder informal learning processes more than they help by reinforcing the type of training model that Brown and Duguid (2000) and others argue against. Although we see a place for highly structured e-learning environments, we also see a need for teachers to have a set of online learning and collaboration capabilities that they can own and tailor to meet their own needs and the needs of the community. Sophisticated knowledge management and collaboration capabilities are commonly found in online environments intended for business (Cothrel \& Williams, 1999), scientific (Finholt, Lewis, \& Mott; 1995), and even elementary classroom (Hewitt, this volume; Gomez, Fishman, \& Pea, 1998) learning communities, but they are not common in environments intended to support communities of education practitioners.

Guidepost 2. History and Culture. A community of practice develops, and continually reproduces, its own dominant cultural artifacts, norms, and values over time. Members of a community of practice inherit norms and practices that have been previously negotiated and agreed on through the experiences of those who have come before them (Barab \& Duffy, 2000). 
In S. Barab, R. Kling, and J. Gray (Eds.) Designing for Virtual Communities in the Service of Learning. Cambridge University Press. Also in The Information Society, 203-220, 2003

TIS DRAFT 6/03

Online technology can enable new members of a community of practice to learn established norms, values, and practices of the culture through participation in the community's online activities. New members also inherit the community's memory, embodied in historical artifacts that the community reuses and modifies over time. Policy-makers and change agents could also benefit from analyzing the records of online discourse and digital artifacts that are modified by the community through use over time.

As we have seen, however, cultural norms and values can become very resistant to change in communities with a long and rich history, requiring drastic measures on the part of school reform leaders to implement and sustain reform efforts. Online technology could help encourage members of a community of practice to unlearn old norms and learn new norms, values, and practices through participation in new forms of activity (e.g., from hierarchical to collegial interaction patterns, structured to conversational discourse, passive to active participation).

Thus, education communities of practice could benefit from online capabilities that make it possible to create, manage, reuse, and modify workplace artifacts (e.g., lesson plans, assessments, action research, student and teacher portfolios) and records of community discourse. Developers of online environments must also be aware of the match between historically evolved norms and values and those that their technology promotes. The two need not, and in some cases should not, match, but if the designers are not aware of the mismatch, they may not build appropriate scaffolds to help users bridge the mismatch.

Guidepost 3. Membership Identity and Multiplicity. Education communities of practice differ from other groupings of educators (e.g., study groups, work teams, or occupational societies) in the heterogeneity and diversity of their membership. By this we mean that community membership spans a continuum of types of expertise and levels of competency rather than being defined by domain or rank. Groups within communities form and disband; participants, objectives, tools, and division of labor change over time. Community members take on multiple roles - such as broker, moderator, mentor, and learner - in different contexts. The transition between roles is not scripted, designated, or assigned as in formal training or organizational hierarchies. Membership tends to cross formal organizational and social boundaries rather than being defined by them.

Thus, online infrastructure needs to be designed to help members of a community of practice build and manage their professional identity, find and collaborate with one another, and function 
In S. Barab, R. Kling, and J. Gray (Eds.) Designing for Virtual Communities in the Service of Learning. Cambridge University Press. Also in The Information Society, 203-220, 2003

TIS DRAFT 6/03

in multiple roles. Such capabilities are not needed by homogeneous communities of purpose in which roles are relatively static (e.g., projects, courses, formal organizations). Community of practice infrastructure must support the process of forming a group for a specific activity, based on the expertise and prior experiences of the members of the community; it must also support the transfer of knowledge from groups back into the larger community. For example, Barab et al. (this volume) describe a design process in which they moved away from designing spaces through which all members of a large community could interact to supporting spaces in which smaller, bounded groups could form and interact around a particular practice, topic, or issue. In contrast, groupware systems are typically designed to support defined groups, not the larger social entity from which groups are formed. They may support sharing and awareness within a group but not across groups, thereby inhibiting peripheral participation by novices and outside experts and constraining knowledge diffusion throughout the community.

Guidepost 4. Community Reproduction and Evolution. A major objective of many professional development interventions is the transformation of a community of purpose into a community of practice, which rarely occurs; the time, cost, commitment, and effort required are simply too great for most projects. Instead, the literature suggests that projects leverage the ongoing growth and reproductive processes of extant communities from which the participants come. One hallmark of a community of practice that distinguishes it from other forms of community is the ability to grow, evolve, and reproduce its membership. A community of practice grows and reproduces itself as new members join and embark on paths toward mastery and leadership and as existing members join other communities (Lave \& Wenger, 1991; Schlager et al., 1998, 2002; Barab \& Duffy, 2000). A major premise of this chapter is that professional development efforts need to leverage this existing capacity for sustainability more effectively.

Online technology could be used to support a division of labor in which accomplished members of a local community of practice participate peripherally in formal professional development interventions in which their less-accomplished colleagues are participating. This arrangement would help new teachers form relationships with more senior members of their new community (not just with other new teachers and professional development providers). Bringing members of the community into formal teacher education and professional development interventions could also help the community reproduce itself by helping to decrease the epidemic rates of teacher attrition in many underserved areas. 
In S. Barab, R. Kling, and J. Gray (Eds.) Designing for Virtual Communities in the Service of Learning. Cambridge University Press. Also in The Information Society, 203-220, 2003

TIS DRAFT 6/03

Online technology can also support community evolution and reproduction by enabling the community to build its capacity for resource-intensive informal professional development activities such as mentoring and coaching. Harnessing the diverse expertise available among community of practice members to engage in mentoring and coaching on a districtwide scale requires a different type of support infrastrstructure than is commonly implemented today. Most mentoring programs assume that expertise is a very limited resource (mentors must be "officially designated"); therefore, most programs employ a hub-and-spoke model in which a single mentor is assigned to some number of mentees. This model works well in small projects, in which a sufficient number of mentors can be recruited and trained, and the technology needed to support such a model is fairly straightforward (e.g., the participants need to be able to communicate and share artifacts). However, the hub-and-spoke model is inherently unscalable, especially in school districts with high turnover rates. In districts with the most need, there simply are not enough designated mentor teachers to go around.

A networked model, which makes use of technology to create a web or network of expertise from across the district, would make better, more efficient use of the district's human capacity, but it also requires more sophisticated technology than the hub-and-spoke model to implement. Matching seekers to providers, load balancing, reputation and reward management, and quality control are some of the challenges that must be addressed for a networked model to work.

Guidepost 5. Social Networks. Professionals in a community of practice develop, manage, and participate in multiple overlapping social networks within and across community of practice boundaries (Wenger, 1998; Cothrel \& Williams, 1999). We believe that online technologies can influence the formation, structure, and evolution of social networks within education communities of practice in either positive or negative ways. For example, built-in administrative control structures in some intranet systems may tend to encourage top-down, hierarchical communication and dissemination of information. Such structures may not allow ad hoc groups to set up their own private (or public) channels of communication and information sharing. Moreover, intranet systems can exclude outsiders from participating in discourse through gatekeeping policies and security mechanisms. Finally, intranets can inhibit communication among members of a community by blocking access from outside the school or district server, forcing teachers to seek other means of communication after school hours (such as Tapped In for many of its users). List server, chat, and discussion board technologies may also facilitate or constrain social networks 
In S. Barab, R. Kling, and J. Gray (Eds.) Designing for Virtual Communities in the Service of Learning. Cambridge University Press. Also in The Information Society, 203-220, 2003

within communities of practice in ways that are not fully understood, suggesting the need for both new strategies and technologies to track and analyze technology-mediated social networks.

Analyzing the online activities among members of a community of practice and across communities can help to uncover patterns of interaction, group and individual relationships, and roles played by different members - the social structures through which knowledge is generated and spread through the community (Koku \& Wellman, this volume; Wellman, 1997; Wellman \& Gulia, 1999; Bozeman, Dietz, \& Gaughan, 1998). Thus, the size, strength, density, and structure of social networks may serve as indicators of community health and growth.

Assessing social roles or positions in the network can provide information about a group and the place of group members in the overall community. Members with similar patterns of relationships may share a particular role or social position. An individual who has close ties to those at the center of a network may be in a better position to acquire new knowledge, whereas an individual who has direct ties to other members in the periphery may be in a better position to disseminate information (Granovetter, 1973, 1982). Understanding the substructures in a network can also be important to understanding how the network is likely to behave. For example, a clique is a subgroup in a network in which everyone has connections to everyone else. A network with overlapping cliques may experience less conflict and enable innovations to spread more readily than a network with nonoverlapping cliques because members are part of multiple cliques.

Moreover, it is possible that members who belong to multiple cliques may have more opportunities for learning.

We are beginning to explore what social network analysis tools and techniques, in conjunction with other methodologies, can tell us about education communities of practice (Tatar et al., 2002). For example, social network analysis tools might help identify community members who play central roles, who are members of several groupings, or who are in the periphery and, therefore, in need of support. If we look at a social network over time, we expect to see members' centrality in the network change; peripheral members may move toward the center, and central members may move to the periphery or leave. New members may join a group, or members from one group may join another group, and all of this movement could change information flow in a network. In addition, we might find similar network patterns among "successful" groups and then be able to use social network analysis as a tool to analyze groups as they are developing and intervene if a 
In S. Barab, R. Kling, and J. Gray (Eds.) Designing for Virtual Communities in the Service of Learning. Cambridge University Press. Also in The Information Society, 203-220, 2003

TIS DRAFT 6/03

group does not show structures that promote success. Groups, their purposes, and their members will need to be categorized, and metrics of what constitutes a successful group need to be created.

Guidepost 6. Leaders and Contributors. Leadership is a central aspect of membership identity (Guidepost 3) that promotes social networking (Guidepost 5) and community reproduction (Guidepost 4). We have chosen to discuss it separately to highlight the differences between community leadership and the more traditional concepts of organizational (e.g., department heads, principals, district staff) and academic (instructor-student, mentor-mentee) leadership. More importantly, we want to raise the issue of whether and how online technology can support, and help districts build capacity for, community leadership.

Community leadership may intersect with, but is not synonymous with, an organization's formal management structure. Community leaders perform organizing, governance, networking, brokering, and other social support services (Lieberman, 1996; Spillane, Halverson, \& Diamond, 1999; Schlager et al., 1998, 2002) for the community. For example, leaders model and reinforce community rules and norms of practice; they encourage and support the growth of others toward leadership. Leadership can also be conveyed by someone through contributions to the community (e.g., volunteering expertise, materials, or even emotional support). Consequently, community leaders can be difficult for others (especially outsiders) to spot, both because they may have no formally recognized position or title and because their contributions may only have been experienced by certain other members of the community.

Most e-learning technologies are designed to support traditional instructional leadership, in which roles and associated capabilities are well defined, usually in advance. For example, course instructors are given administrative capabilities and controls that students do not have; professional development staff members typically have the power to create discussion forums, while participants do not. Similarly, most intranet systems have levels of permissions that reflect the organization's formal leadership hierarchy. There are no designated and immutable roles and hierarchies in communities of practice; technology should not force people into them. Leadership might take the form of setting up and moderating one's own study group, developing and publishing materials, or offering one's services to other community members in a particular area of expertise. Environments that support communities of practice should enable any member of the community to have the technical capabilities and social support required to take on leadership roles in a given context. 
In S. Barab, R. Kling, and J. Gray (Eds.) Designing for Virtual Communities in the Service of Learning. Cambridge University Press. Also in The Information Society, 203-220, 2003

TIS DRAFT 6/03

Guidepost 7. Tools, Artifacts, and Places. When we think of how technology can support communities of practice, what typically comes to mind is the design of tools and artifacts (e.g., curriculum, assessments, rubrics, and teaching and learning samples) that the members of the community might use to help them learn. We believe that equally important is consideration of how and when new tools and artifacts are introduced to, and assimilated into the practice of, members of a community. Technological tools and learning artifacts are frequently introduced to groups of teachers with little or no advance planning for how those tools and artifacts will be introduced into, and become an integral part of, the overarching culture of a community. As a result, different groups within and across schools in a district champion their own favorite tools and artifacts to accomplish the same functions, and the community as a whole suffers from the fragmentation and isolation among factions. From a community of practice perspective, we should be concerned with these issues. Communication, productivity, coordination, and knowledge generation depend on the broad use of a common palette of tools and the generation, reuse, and refinement of community artifacts, not only within projects but also across projects over time. Thus, professional development providers should think hard about whether and when to introduce new tools and artifacts rather than using those that are already part of the culture. When new tools and artifacts are warranted, designers need to think about compatibility, interoperability, and overlap with existing infrastructure, as well as how the tools could be used in contexts other than the current project.

Public and private meeting places (physical and virtual) are components of the permanent infrastructure of a community of practice (Schlager \& Schank, 1997; Schlager et al., 1998) that are not well represented in online design. Online education technologies tend to focus on representing "the classroom." In the physical world, classrooms and teachers' lounges tend not to be the preferred venues for professional collaboration; consequently, they may not be the best metaphors for online meeting places. Instead, communities of practice may require virtual third places (Oldenburg, 1997) and the social structures that those places afford. Lieberman's (1996; Lieberman \& Grolnick, 1999) research on teacher networks suggests that meeting in community gathering places outside the workplace can help build professional relationships and socialize new members into the fold, thereby solidifying teachers' commitment to the community. Similarly, Orr's (1996) copier repair technicians were able to share "war stories" because they were able to gather in the lunchroom. The Tapped In and Inquiry Learning Forum (Barab et al., this volume) 
In S. Barab, R. Kling, and J. Gray (Eds.) Designing for Virtual Communities in the Service of Learning. Cambridge University Press. Also in The Information Society, 203-220, 2003

TIS DRAFT 6/03

projects represent two anchor points in the design and use of different types of online third places for education professionals. More research is needed to understand how online technology can be used to support the range of professional activities that take place in education communities of practice.

Guidepost 8. The Practice. A community of practice can be distinguished from other groupings of professionals that we call communities of purpose or occupational communities (Van Maanen \& Barley, 1984) by a mutual engagement in a collective enterprise (Wenger, 1998). We might say that the practice of a school is educating children, and the education professionals in a school are members of that practice. ${ }^{6}$ Or one might argue that school administration is a practice separate from classroom teaching. Beyond the school, the lines become even more blurred. Is the enterprise of managing a district a practice separate from the enterprise of educating children within each school? Are all members of a state science teacher association mutually engaged in a single practice? Are district staff developers, professional development consultants, university faculty who conduct summer institutes, and other professionals practitioners of yet another practice - that of training teachers? We raise these questions not simply to encourage philosophical debate, but rather to better understand the boundaries and scope of the collective enterprise that community of practice infrastructure is intended to support.

When researchers observe schools that violate community of practice characteristics-where teachers, administrators, and librarians rarely interact informally; where professional development is taken outside the workplace and placed in the hands of outside providers - we are tempted to conclude that those who teach children, those who run schools, and those who train teachers should not be considered one community of practice. If they are practitioners of the same practice, we would expect educators of children, administrators, and teacher trainers to share the community characteristics listed here. If, however, those practitioners are engaged in separate practices, we would expect to find fundamental differences between the communities in norms of practice, values, tools of the trade, professional relationships, and leaders. Clearly, research has most frequently found the latter to be the case.

These findings pose a dilemma for school reform researchers and technologists alike. Should we generalize from the observation of how things are today to conclude that school districts are

\footnotetext{
${ }^{6}$ We distinguish our use of the term practice from the individual practices, or activities, that members of the practice engage in as part of their work.
} 
In S. Barab, R. Kling, and J. Gray (Eds.) Designing for Virtual Communities in the Service of Learning. Cambridge University Press. Also in The Information Society, 203-220, 2003

TIS DRAFT 6/03

made up of multiple, only loosely connected practices? Our understanding of the literature suggests that doing so would be a mistake (perhaps one that has been made in large-scale professional development and reform efforts). The practice - the collective enterprise - of educating children demands that members of multiple occupational communities and levels of management hierarchy work together in ways that transcend occupational or managerial structures. That they do not, in many cases, appear to be engaged in a joint practice may be a failing of the formal system, not a desired state of affairs (see Elmore, 2000). Thus, we believe that resolving the question of what is the practice that our technologies are being designed to support is not simply an academic exercise but rather a necessary design inquiry. Fundamental differences between practices should lead technologists to make different design choices tailored to the characteristics of each practice. One need only look at the differences between online course management systems used for teacher education and professional development and the much more advanced visualization, modeling, and knowledge-building systems developed for inquiry-based K-12 science classrooms to see how differently designers think about the two aspects of a teacher's practice: they are treated as separate and unrelated. We know that this sort of fractionation is not desirable if we seek overall improvement in our education systems.

In rejecting the premise that district management and professional development are separate from the practice of educating children, we are forced to think anew how, and for whom, we design sociotechnical infrastructure. It no longer makes sense to build separate systems to support school principals, beginning teachers, math teachers, professional development courses, and classroom practice. In developing technology to support community-based teacher professional development, we must support the mutual engagement of all stakeholders in the practice of educating children, not merely the individual parts of the practice in isolation from one another. At least for the purposes of analysis and design, we must treat all stakeholder groups as a single community of practice.

\section{Toward a New Education Community Crossroads}

In his article on school leadership, Elmore (2000) characterizes large-scale improvement as a property of organizations, capturing several of the characteristics of communities of practice enumerated previously in a single paragraph: 
Organizations that improve do so because they create and nurture agreement on what is worth achieving, and they set in motion the internal processes by which people progressively learn how to do what they need to do in order to achieve what is worthwhile. ... Improvement occurs through organized social learning, not through the idiosyncratic experimentation and discovery of variously talented individuals. Experimentation and discovery can be harnessed to social learning by connecting people with new ideas to each other in an environment in which the ideas are subjected to scrutiny, measured against the collective purposes of the organization, and tested by the history of what has already been learned and is known. (p. 25)

Elmore clearly puts the cart of experimentation and discovery (what we have been calling innovation or intervention) behind the horse of established social learning processes and structures within a district. Formal professional development programs represent a form of experimentation leading to discovery of how to improve instruction. But if that and other forms of experimentation and innovation remain disconnected from the larger learning context - the norms and practices of the collective community - then the system will not improve.

This chapter represents the start of a journey to find ways in which we might leverage online technology, activities, and services to help districts realize cohesive, well-aligned, career-long professional development and system-wide improvement. We have used the community of practice framework to expand the focus of analysis beyond individual schools, professional development programs, or online communities. We have argued that community of practice is not just another term used to convey a sense of professional kinship or shared interest; it is an integral, evolving entity that spans stakeholder groups within a school system. It may promote improvement or militate against instructional improvement in a number of ways. Even dysfunctional communities of practice can, with leadership toward a common improvement goal, grow over time to be effective contexts for learning and strong catalysts for district-wide improvement. We also conjecture that specific aspects of communities (e.g., tools, rules, and division of labor) can help diagnose the health of an education community of practice (how well it is functioning), signaling whether a professional development intervention or other innovation is likely to be accepted, take root, and spread. 
In S. Barab, R. Kling, and J. Gray (Eds.) Designing for Virtual Communities in the Service of Learning. Cambridge University Press. Also in The Information Society, 203-220, 2003

TIS DRAFT 6/03

As a starting point for our journey, we have enumerated eight characteristics of an education community of practice that represent guideposts for designing infrastructure to support communities of practice. We have taken the strong position that the eight characteristics are not a menu from which technologists can choose which ones to address in developing tools and environments intended to support an education community of practice. We believe that community of practice infrastructure must address all of the characteristics. In the sociotechnical design of Tapped In, we have worked on all of these dimensions, and we have been more successful in some areas than in others. Tapped In lacks certain communication, database, and search tools that we believe are necessary components of a community of practice infrastructure. For example, Tapped In needs stronger tools for content-specific authoring and reflective inquiry to support a local practice more effectively. We have focused on leadership and culture in relation to the online community, but not in relation to one's local community.

Moving forward, we must develop new ways that online technology and social structures can be used to help (1) identify, diagnose, and mend dysfunctional structural aspects of an education community of practice and (2) support the community in its role as a context and catalyst for improved instruction and professional development. We recognize, however, that understanding and addressing the characteristic structures of education communities of practice is only half the battle. The greater challenge is to understand the processes through which a districtwide community of practice works, evolves, and interacts with policies, programs, and informal activities to help teachers become accomplished educators and adult learners.

Education technology researchers know well that even technology-mediated interventions that are well designed to support the envisioned structures and activities of a school community often are not taken up by the community because of what Orlikowski (1992) calls the duality of technology - the influence of the technology on the organization and the influence of the organization on the technology. "The ongoing interaction of technology with organizations must be understood dialectically, as involving reciprocal causation, where the specific institutional context and the actions of knowledgeable, reflexive humans always mediate the relationship" (p. 423). To meet this challenge, we must step outside the online world to study the sociocultural processes of communities of practice in both well-functioning and dysfunctional districts. By understanding the structures and the processes of education communities of practice, we hope to construct analytical tools to diagnose community health, formulate strategies to help strengthen 
In S. Barab, R. Kling, and J. Gray (Eds.) Designing for Virtual Communities in the Service of Learning. Cambridge University Press. Also in The Information Society, 203-220, 2003

the community, and develop social models and technological tools that support the community's role in the professional development of its members. Our goal is to build a new crossroads that brings together, and helps forge stronger relationships among, education practitioners, providers, and researchers within a local community of practice to engage in the work of instructional improvement.

\section{Acknowledgments}

The work presented in this paper was supported in part by National Science Foundation Grants REC-9725528 and REC-0106926. We are grateful to Sasha Barab, Jim Gray, and Rob Kling for their commentary on drafts of the chapter. We are indebted to the other members of our own community of practice, the Tapped In project team at SRI: Patti Schank, Melissa Koch, Deb Tatar, Richard Godard, Kari Holsinger, and B. J. Berquist. Finally, we thank the many Tapped In community leaders, from whom we have learned much about the culture of K-12 education professionals. We dedicate this chapter to Natalie and Adi.

\section{References}

American Association of Colleges for Teacher Education (AACTE). (2000). Log on or lose out. Washington, DC: AACTE Publications.

Ball, D. L., \& Cohen, D. K. (1999). Developing practice, developing practitioners: Toward a practice-based theory of professional education. In L. Darling-Hammond \& G. Sykes (Eds.), Teaching as the learning profession: Handbook of policy and practice, pp. 3-32. San Francisco, CA: Jossey-Bass.

Barab, S. A., \& Duffy, T. M. (2000). From practice fields to communities of practice. In D. Jonassen \& S. Land (Eds.), Theoretical foundations of learning environments, pp. 29-56. Mahwah, NJ: Erlbaum.

Barab, S., MaKinster, J., \& Scheckler, R. (this journal). Designing system dualities: Characterizing an online professional development community. In S. A. Barab, R. Kling, \& J. Gray (Eds.), Designing for virtual communities in the service of learning. Cambridge, MA: Cambridge University Press.

Blanton, W. E., Mooreman, G., \& Trathen, W. (1998). Telecommunications and teacher education: A social constructivist review. In P. D. Pearson \& A. Iran-Nejad (Eds.), Review of research in education, 23 (pp. 235-275). Washington, DC: AERA.

Blumenfeld, P. C., Fishman, B. J., Krajcik, J. S., \&. Marx, R. W. (2000). Creating usable innovations in systemic reform: Scaling up technology-embedded project-based science in urban schools. Educational Psychologist, 35(3), 149-164.

Bozeman, B., Dietz, J. S., \& Gaughan, M. (1998, August). Scientific and technical human capital: An alternative model for research evaluation. Draft for presentation at the American Political Science Association, September 5, Atlanta GA. 
In S. Barab, R. Kling, and J. Gray (Eds.) Designing for Virtual Communities in the Service of Learning. Cambridge University Press. Also in The Information Society, 203-220, 2003

Bransford, J., Brown, A., \& Cocking, R. (Eds.). (1999). How people learn: Brain, mind, experience, and school. Washington, DC: National Academy Press.

Brown, J. S., \& Duguid, P. (1991). Organizational learning and communities-of-practice: Toward a unified view of working, learning and innovation. Organization Science, 2(1), pp. 40-57.

Brown, J. S., \& Duguid, P. (2000). The social life of information. Cambridge, MA: Harvard Business School Press.

Cochran-Smith, M., \& Lytle, S. L. (1999). Relationships of knowledge and practice: Teacher learning in communities. In A. Iran-Nejad \& P. D. Pearson (Eds.), Review of research in education, 24 (pp. 249-305). Washington, DC: AERA.

Cole, M., \& Engeström, Y. (1993). A cultural-historical approach to distributed cognition. In G. Solomon (Ed.), Distributed cognitions: Psychological and educational considerations, pp. 146. Cambridge, UK: Cambridge University Press.

Constant, D., Sproull, L., \& Kiesler, S. (1996). The kindness of strangers: The usefulness of electronic weak ties for technical advice. Organization Science, 7(2), 119-135.

Corcoran, T. B., Shields, P. M., \& Zucker, A. A. (1998, March). The SSIs and professional development for teachers. Menlo Park, CA: SRI International.

Cothrel, J., \& Williams, R. (1999). Online communities: Helping them form and grow. Journal of Knowledge Management, 3(1), 54-60.

Darling-Hammond, L., \& Ball, D. L. (1997, June). Teaching for high standards: What policymakers need to know and be able to do. Available at http://www.negp.gov/reports/highstds.htm.

Darling-Hammond, L., \& Sykes, G. (Eds.) (1999). Teaching as the learning profession: Handbook of policy and practice. San Francisco, CA: Jossey-Bass.

Derry, S. J., Gance, S., Gance, L. L., \& Schlager, M. S. (2000). Toward assessment of knowledge building practices in technology-mediated work group interactions. In S. Lajoie (Ed.), Computers as cognitive tools II, pp. 29-68. Mahwah, NJ: Erlbaum.

Donnelly, M. B., Dove, T., Tiffany, J., Adelman, N., \& Zucker, A. (2000, January). Evaluation of key factors impacting the effective use of technology in schools. Subtask 5: Professional development study literature review. Draft report. Menlo Park, CA: SRI International.

Dunlap, D. R., Neale, D. C. \& Carroll, J. M. (2000). Teacher collaboration in a networked community. Educational Technology and Society 3(3), Special Issue on On-Line Collaborative Learning Environments.

Elmore, R. F. (1996). Getting to scale with good educational practice. Harvard Educational Review, 66(1), 1-26.

Elmore, R. F. (2000). Building a new structure for school leadership. Washington, DC: Albert Shanker Institute.

Elmore, R. F., \& Burney, D. (1999). Investing in teacher learning: Staff development and instructional improvement. In L. Darling-Hammond \& G. Sykes (Eds.), Teaching as the learning profession: Handbook of policy and practice, pp. 263-291. San Francisco, CA: Jossey-Bass.

Evertson, C. M., Smithey, M. W., \& Hough, B. W. (2000). Exploring the use of Web-based conferences for new teacher professional development. Final Report, NPEAT Project 2.4.3. National Partnership for Excellence and Accountability in Teaching (NPEAT). Washington, DC: U.S. Department of Education.

Engeström, Y. (1987). Learning by expanding: An activity-theoretical approach to developmental research. Helsinki: Orienta-Konsultit. 
In S. Barab, R. Kling, and J. Gray (Eds.) Designing for Virtual Communities in the Service of Learning. Cambridge University Press. Also in The Information Society, 203-220, 2003

Engeström, Y. (1999). Expansive visibilization of work: An activity-theoretical perspective. Computer Supported Cooperative Work (CSCW), 8(1-2), 63-93.

Feldman, A., Konold, C., \& Coulter, B. (2000). Network science a decade later: The Internet and classroom learning. Mahwah, NJ: Erlbaum.

Finholt, T. A., Lewis, S. A., \& Mott, W. H. (1995). Distance learning in the Upper Atmospheric Research Collaboratory. Unpublished manuscript. Collaboratory for Research on Electronic Work. Ann Arbor, MI: University of Michigan.

Fusco, J., Gehlbach, H., \& Schlager, M. (2000). Assessing the impact of a large-scale online teacher professional development community. In Proceedings of the 11th International Conference for the Society for Information Technology and Teacher Education (pp. 21782183).

Gallego, M. A., Hollingsworth, S., \& Whitenack, D. A. (2001). Relational knowing in the reform of educational cultures. Teachers College Record, 103(2), 240-266.

Garet, M. S., Porter, A. C., Desimone, L., Birman, B. F., \& Yoon, K. S. (2001, Winter). What makes professional development effective? Results from a national sample of teachers. American Educational Research Journal, 38(4), 915-945.

Gomez, L., Fishman, B., \& Pea, R. (1998). The CoVis project: Building a large-scale science education testbed. Interactive Learning Environments, 6(1-2), 59-92.

Granovetter, M. (1973). The strength of weak ties. American Journal of Sociology, 78, pp. 13601380.

Granovetter, M. (1982). The strength of weak ties: A network theory revisited. In P. M. N. Lin (Ed.), Social structure and network analysis (pp. 105-130). Beverly Hills, CA: Sage.

Gray, J., \& Tatar, D. (in press). Sociocultural analysis of online professional development: A case study of personal, interpersonal, community, and technical aspects. In S. A. Barab, R. Kling, \& J. Gray (Eds.), Designing for virtual communities in the service of learning. Cambridge, MA: Cambridge University Press.

Grossman, P., Wineburg, S., \& Woolworth, S. (2000, April). In pursuit of teacher community. Paper presented at the Annual Meeting of the American Educational Research Association, New Orleans.

Hartocollis, A. (2000, November 22). Teachers find toughest task is learning from each other. New York Times on the Web. At http://www.nytimes.com/2000/11/22/nyregion.

Hawkins, J. (1996). Dilemmas. In C. Fisher, D. C. Dwyer, \& K. Yocam (Eds.), Education and technology (pp. 33-50). San Francisco: Jossey-Bass.

Hewitt, J. (in press). An exploration of community in a Knowledge Forum classroom: An activity system analysis. In S. A. Barab, R. Kling, \& J. Gray (Eds.), Designing for virtual communities in the service of learning. Cambridge, MA: Cambridge University Press.

Hoadley, C. M., \& Pea, R. D. (2002). Finding the ties that bind: Tools in support of a knowledgebuilding community. In K. A. Renninger \& W. Shumar (Eds.), Building virtual communities: Learning and change in cyberspace, pp. 321-354. New York: Cambridge University Press.

Honey, M., Carrigg, F., \& Hawkins, J. (1998). Union City Online: An architecture for networking and reform. In C. Dede (Ed.), The 1998 ASCD yearbook: Learning with technology (pp. 121139). Alexandria, VA: ASCD.

Koku, E. F., \& Wellman, B. (in press). Scholarly networks as learning communities: The case of TechNet. In S. A. Barab, R. Kling, \& J. Gray (Eds.), Designing for virtual communities in the service of learning. Cambridge, MA: Cambridge University Press. 
In S. Barab, R. Kling, and J. Gray (Eds.) Designing for Virtual Communities in the Service of Learning. Cambridge University Press. Also in The Information Society, 203-220, 2003

TIS DRAFT 6/03

Koppich, J., Asher, C., \& Kerchner, C. (2002). Developing careers, building a profession: The Rochester Career in Teaching plan. New York: National Commission on Teaching \& America's Future.

Lave, J., \& Wenger, E. (1991). Situated learning: Legitimate peripheral participation. Cambridge, UK: Cambridge University Press.

Lieberman, A. (1996). Creating intentional learning communities. Educational Leadership, 54(3), 51-55.

Lieberman, A., \& Grolnick, M. (1999). Networks and reform in American education. In L. Darling-Hammond \& G. Sykes (Eds.), Teaching as the learning profession: Handbook of policy and practice, pp. 292-312. San Francisco, CA: Jossey-Bass.

Little, J. W. (1990). The persistence of privacy: Autonomy and initiative in teachers' professional relations. Teachers College Record, 91(4), 509-536.

Little, J. (1993). Teachers' professional development in a climate of educational reform. Educational Evaluation and Policy Analysis, 15(2), 129-151.

Little, J. W. (2001, September). Inside teacher community: Representations of classroom practice. Presented at the conference of International Study Association on Teachers and Teaching, Faro, Portugal.

Lortie, D. C. (1975). Schoolteacher: A sociological study. Chicago, IL: University of Chicago Press.

Loucks-Horsley, S., Hewson, P. W., Love, N., \& Stiles, K. E. (1998). Designing professional development for teachers of science and mathematics. Thousand Oaks, CA: Corwin.

Marx, R. W., Blumenfeld, P. C., Krajcik, J. S., \& Soloway, E. (1998). New technologies of teacher professional development. Teaching and Teacher Education, 14, 33-52.

McLaughlin, M. W., \& Mitra, D. (2001). Theory-based change and change-based theory: Going deeper, going broader. Journal of Educational Change, 1(2), 1-24.

McLaughlin, M. W., \& Talbert, J. E. (2001). Professional communities and the work of high school teaching. Chicago, IL: University of Chicago Press.

Mwanza, D. (2001). Where theory meets practice: A case for an Activity Theory based methodology to guide computer system design. In M. Hirose (Ed.), Proceedings of INTERACT'2001: Eighth IFIP TC 13 International Conference on Human-Computer Interaction. Oxford, UK: IOS Press.

National Commission on Mathematics and Science Teaching for the 21st Century. (2000). Before it's too late. U.S. Department of Education. Available at www.ed.gov/americacounts/glenn.

National Commission on Teaching and America's Future (NCTAF). (1996). What matters most: Teaching for America's future. New York: Author.

Oldenburg, R. (1997). The great good place. New York: Marlowe.

Orlikowski, W. J. (1992). The duality of technology: Rethinking the concept of technology in organizations. Organization Science, 3(3), 398-427.

Orr, J. (1996). Talking about machines: An ethnography of a modern job. Ithaca, NY: IRL Press.

Palloff, R. M., \& Pratt, K. (1999). Building learning communities in cyberspace. San Francisco, CA: Jossey-Bass.

President's Committee of Advisors on Science and Technology (PCAST), Panel on Educational Technology. (1997, March). Report to the President on the use of technology to strengthen K12 education in the United States. Available at http://www.ostp.gov/PCAST/k-12ed.html.

Putnam, R. T., \& Borko, H. (2000). What do new views of knowledge and thinking have to say about research on teacher learning? Educational Researcher, 29(1), 4-15. 
In S. Barab, R. Kling, and J. Gray (Eds.) Designing for Virtual Communities in the Service of Learning. Cambridge University Press. Also in The Information Society, 203-220, 2003

TIS DRAFT 6/03

Rényi, J. (1996). Teachers take charge of their learning: Transforming professional development for student success. NEA Foundation for the Improvement of Education. Available at http://nfie.org/publications/takecharge.htm.

Riel, M., \& Becker, H. (2000, April)._The beliefs, practices, and computer use of teacher leaders. AERA presentation, New Orleans. Available online at http://www.crito.uci.edu/tlc/findings/aera.

Riel, M., \& Polin, L. (in press). Online communities: Common ground and critical differences in designing technical environments. In S. A. Barab, R. Kling, \& J. Gray (Eds.), Designing for virtual communities in the service of learning. Cambridge, MA: Cambridge University Press.

Ruopp, R., Gal, S., Drayton, B., \& Pfister, M. (1993). LabNet: Toward a community of practice. Hillsdale, NJ: Lawrence Erlbaum.

Schank, P., Fenton, J., Schlager, M., \& Fusco, J. (1999). From MOO to MEOW: Domesticating technology for online communities. In C. Hoadley (Ed.), Computer Support for Collaborative Learning (CSCL) 1999 (pp. 518-526). Hillsdale, NJ: Erlbaum.

Schlager, M. S., Fusco, J., \& Schank, P. (1998). Cornerstones for an online community of education professionals. IEEE Technology and Society, 17, 15-21, 40.

Schlager, M., Fusco, J., \& Schank, P. (2002). Evolution of an online education community of practice. In K. A. Renninger \& W. Shumar (Eds.), Building virtual communities: Learning and change in cyberspace (pp. 129-158). New York: Cambridge University Press.

Schlager, M. S., \& Schank, P. K. (1997). TAPPED IN: A new online teacher community concept for the next generation of Internet technology. In Proceedings of CSCL '97, The Second International Conference on Computer Support for Collaborative Learning (pp. 230-241). Hillsdale, NJ: Erlbaum.

Schwen, T. M. (this journal). Communities of practice: A metaphor for online design? In S. A. Barab, R. Kling, \& J. Gray (Eds.), Designing for virtual communities in the service of learning. Cambridge, MA: Cambridge University Press.

Scribner, J. P., Cockrell, K. S., Cockrell, D. H., \& Valentine, J. W. (1999). Creating professional communities in schools through organizational learning. Educational Administration Quarterly, 35(1), 130-161.

Shields, P. M., Esch, C., Young, V. M., \& Humphrey, D. C. (2000). White paper on teacher induction. Menlo Park, CA: SRI International.

Smylie, M. A., Allensworth, E., Greenberg, R. C., Harris, R., \& Luppescu, S. (2001). Teacher professional development in Chicago: Supporting effective practice. Chicago, IL: Consortium on Chicago School Research.

Spillane, J. P., Halverson, R., \& Diamond, J. B. (1999). Toward a theory of leadership practice: A distributed perspective. Evanston, IL: Northwestern University.

Stein, M. K., Silver, E. A., \& Smith, M. S. (1998). Mathematics reform and teacher development: A community of practice perspective. In J. G. Greeno \& S. V. Goldman (Eds.), Thinking practices in mathematics and science learning (pp. 17-52). Mahwah, NJ: Erlbaum.

Tatar, D. G., Gray, J., \& Fusco, J. (2002). Rich social interaction in a synchronous online community for learning. In G. Stahl (Ed.), Proceedings of the Conference on Computer Support for Collaborative Learning, pp. 633-634. Hillsdale, NJ: Erlbaum.

Van Maanen, J., \& Barley, S. R. (1984). Occupational communities: Culture and control in organizations. Research in Organizational Behavior, 6, 287-365.

Web-based Education Commission. (2000). The power of the Internet for learning: Moving from promise to practice. Washington, DC: Author. 
In S. Barab, R. Kling, and J. Gray (Eds.) Designing for Virtual Communities in the Service of Learning. Cambridge University Press. Also in The Information Society, 203-220, 2003

Wellman, B. (1997). An electronic group is virtually a social network. In S. Kiesler (Ed.), Culture of the Internet (pp. 179-205). Mahwah, NJ: Erlbaum.

Wellman, B., \& Gulia, M. (1999). Net surfers don't ride alone: Virtual communities as communities. In M. A. Smith \& P. Kollock (Eds.), Communities in cyberspace, pp. 167-194. London: Routledge.

Wenger, E. (1998). Communities of practice: Learning, meaning, and identity. New York: Cambridge University Press.

Wilson, S. M., \& Berne, J. (1999). Teacher learning and the acquisition of professional knowledge: An examination of research on contemporary professional development. In A. Iran-Nejad \& P. D. Pearson (Eds.), Review of research in education, 24 (173-209). Washington, DC: AERA. 
In S. Barab, R. Kling, and J. Gray (Eds.) Designing for Virtual Communities in the Service of Learning. Cambridge University Press. Also in The Information Society, 203-220, 2003

TIS DRAFT 6/03

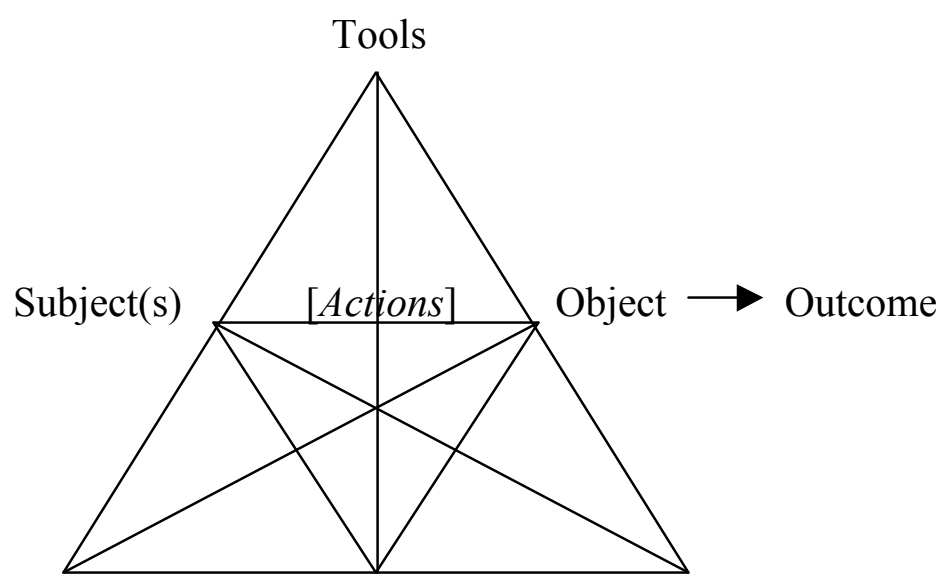

Rules Community Division of Labor

Figure 1. Diagram of Activity System Structure (based on Engeström, 1987) 
In S. Barab, R. Kling, and J. Gray (Eds.) Designing for Virtual Communities in the Service of Learning. Cambridge University Press. Also in The Information Society, 203-220, 2003

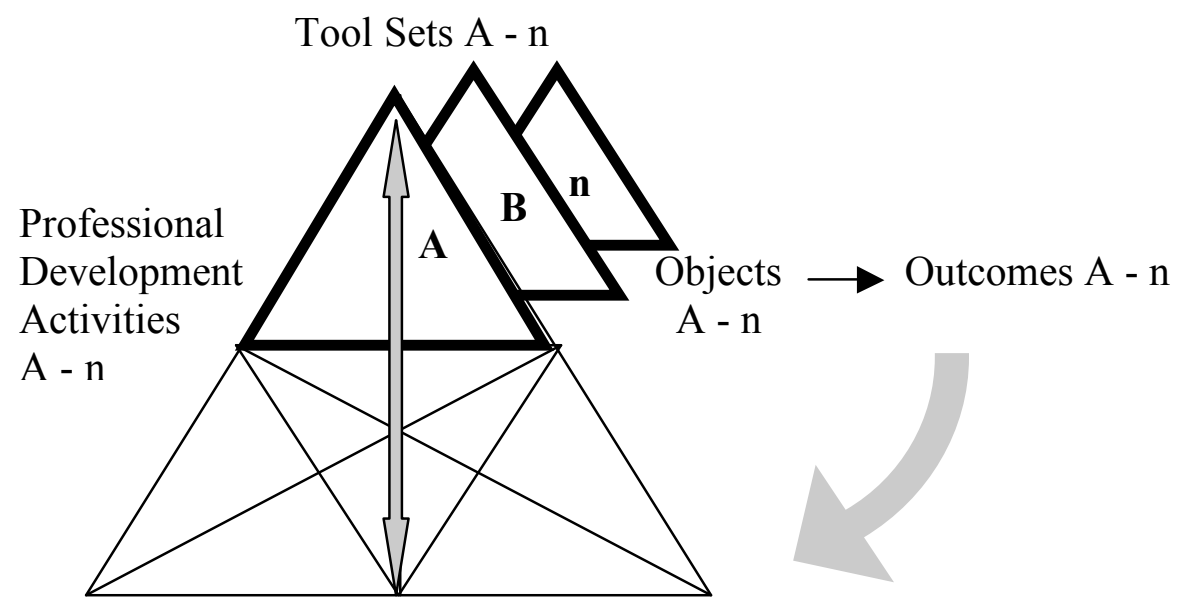

Figure 2. Activivity diagram illustrating the mutußlly veneficicial relationship between professional development activities and a local education community of practice 